\title{
Quimi Crush: atividade lúdica PaRa O ENSINO DE QUÍMICA ORGÂNICA
}

\author{
QUIMI CRUSH: PLAYFUL ACTIVITY FOR TEACHING ORGANIC CHEMISTRY
}

DOI: http://dx.doi.org/10.23926/RPD.2526-2149.2018.v3.n2.p625-642.id264

\author{
Diego Arantes \\ Teixeira Pires \\ Doutor em Química (UnB). \\ Professor EBTT (IFG). \\ diego.pires@ifg.edu.br
}

\section{Leonardo Alves do \\ Nascimento}

Graduando em Sistemas da

Informação (IFG).

leonardo.alvesnti@gmail.co

$\underline{\mathrm{m}}$

\section{Tatyana Mira \\ Medeiros}

Graduanda em Sistemas da

Informação (IFG).

tatymmedeiros@gmail.com

\section{Luiz Fernando Batista \\ Loja}

Doutor em Engenharia

Elétrica (UFU).

Professor EBTT (IFG).

luiz.loja@ifg.edu.br
Resumo: Atualmente paira sobre a área de Ciências Naturais, e principalmente na disciplina de Química, uma grande preocupação em relação ao processo de ensino-aprendizagem de conceitos científicos. Uma solução, por parte dos estudiosos da Educação Química, para sanar essa problemática é desenvolver e apontar materiais que utilizem Novas Tecnologias para incrementar a metodologia das aulas ministradas pelos professores de Ciências. Alguns desses materiais, que podem contribuir com o êxito no processo de ensino-aprendizagem, são os softwares lúdicos educacionais. Nesse sentido, realizou-se o desenvolvimento de um aplicativo para dispositivo móvel, denominado Quimi Crush, para auxiliar na mediação do conteúdo de Funções Orgânicas no Ensino Médio. O jogo didático foi desenvolvido, testado e aplicado com alunos do Ensino Médio e alunos do Ensino Superior. Esse jogo foi bem avaliado por ambos os grupos. Além disso, Quími Crush foi validado como jogo didático, podendo ser uma ferramenta para auxiliar as aulas de Química, tornando-as mais dinâmicas e interessantes.

Palavras-chave: Química Orgânica. Atividades Lúdicas. Tecnologias na Educação.

\begin{abstract}
Nowaday, there is a great concern about the teaching and learning process of scientific concepts in the field of Natural Sciences, and especially in Chemistry classes. For education researchers, a solution to solve this problem is to develop and point out materials that use new technologies to increase the methodology of the classes. Some of these materials, which can contribute to the success in the teaching-learning process, are playful educational softwares. In this sense, it was developed a mobile device application, named Quimi Crush, to assist in mediating the content of Organic Functions in high school classes. The playful game was developed, tested and applied with High School and ungergraduate students. This game was well rated by both groups. In addition, Quimi Crush has been validated as an educational game and can be a tool to help in chemistry classes, making them more dynamic and interesting.
\end{abstract}

Keywords: Organic Chemistry. Playful Activities. Educational Technologies. 


\section{INTRODUÇÃO}

Diversos pesquisadores, que se dedicaram a encontrar ferramentas fora do convencional para o ensino, constataram que os jogos didáticos podem ser artifícios que auxiliam o processo de ensino-aprendizagem (SILVA, CORDEIRO e KIILL; 2015). Os conteúdos tratados na Química abordam aspectos que requerem a abstração, por parte dos alunos, e que na maioria das vezes são difíceis de serem compreendidos. A utilização de jogos pode minimizar essa dificuldade e facilitar a compreensão de determinados conteúdos (CAVALCANTI e SOARES, 2009).

Há algum tempo, os jogos educacionais vêm sendo apontados como uma forte ferramenta pedagógica. Na Grécia Antiga, Aristóteles indicava a utilização de jogos para preparar o cidadão para a vida futura (SILVA, CORDEIRO e KILL, 2015). Platão, em alguns dos seus escritos, comenta a importância de se aprender brincando. Os romanos utilizavam os jogos físicos para formar cidadãos e soldados respeitados e aptos, e se descrevia a utilização de jogos com o objetivo de preparar os soldados para as constantes guerras e invasões romanas. $\mathrm{Na}$ idade média, onde a sociedade sofria forte influência do Cristianismo que impunha uma educação baseada na disciplina, não abriu espaço para a expansão do uso de jogos na educação (CUNHA, 2012). Segundo Dias (1996), escolas episcopais impunham dogmas e se distanciam do desenvolvimento da inteligência. Os mestres ditavam lições e liam cadernos, restando aos alunos a memorização e uma certa obediência (SOARES, 2004).

Os jogos só vieram a ser considerados ferramentas pedagógicas novamente no Renascimento, com o surgimento de novas concepções pedagógicas (CUNHA, 2012). A partir deste momento, o jogo deixa de ser objeto de reprovação, e passa e ser incorporado ao cotidiano dos jovens, não apenas como diversão, mas como tendência natural do ser humano (SOARES, 2004). No século XVI, foi fundado o Instituto dos Jesuítas por Inácio de Loyola. Esse, que era um dos líderes da companhia, entende a importância do jogo para a formação do indivíduo e difunde a sua utilização no sistema educacional da instituição (SILVA, CORDEIRO, KIILL, 2015). O baralho, por exemplo, adquire, nesta época, o status de jogo educativo, por meio do padre franciscano Thomas Murner (SOARES, 2004). Com a importância da imagem em voga, John Locke, pai do empirismo, reforçou essa tese, dizendo que tudo que está na inteligência passa pelos sentidos. Multiplicou-se daí os jogos nas diversas áreas do conhecimento (SOARES, 2004). No século XVIII, foram desenvolvidos os jogos voltados para o ensino de ciência. Inicialmente, esses eram utilizados pela realeza e aristocracia, mas rapidamente tornaram-se populares, deixando de ser um privilégio dos nobres (SILVA, CORDEIRO e KIILL, 2013). 
No século XIX, com o fim da revolução Francesa, surgem muitas inovações pedagógicas, e os jogos passaram a ter maior espaço no meio educacional. No século XX, ocorre novamente uma expansão dos jogos educativos, estimulados pela aparição e expansão de escolas, principalmente infantis (SOARES, 2004). Com isso, os jogos passaram a ser mais discutidos e buscou-se utilizá-los de uma forma mais controlada por parte do professor (CUNHA, 2012).

Na França, Jenan Pieget (1896-1980) apresenta, em várias de suas obras, experiências lúdicas voltadas às crianças. Para Piaget (1975), os jogos podem contribuir para o desenvolvimento intelectual nas crianças e se tornam cada vez mais significativo à medida que elas se desenvolvem (CUNHA, 2012). Esse exposto histórico deixa entender o jogo como parte integrante da história da humanidade. Assim, é importante entender a importância dos jogos no contexto da educação.

Um jogo pode ser considerado educativo quando mantêm um equilíbrio entre duas funções: a lúdica e a educativa. Segundo Kishimoto (1996), a função lúdica está relacionada a diversão e o prazer que o jogo propicia. Se houver um desequilíbrio entre elas, provoca-se duas situações: não há mais ensino, somente jogo, quando a função lúdica predomina em demasia, ou a função educativa elimina toda a ludismo e a diversão, restando apenas o ensino ou um material didático (SOARES, 2004). A parte educativa de um jogo é referente a mediação de conhecimentos, saberes e habilidades. O jogo, neste sentido, deve ser uma atividade controlada pelo professor para que não se torne somente diversão e brincadeira. No entanto, isso não significa dizer que o jogo no ensino perderia seu caráter lúdico e sua liberdade (SILVA, CORDEIRO e KIILL, 2015).

Os jogos educacionais devem estar relacionados ao ensino de conceitos e conteúdos, organizados em regras e atividades programadas, sempre mantendo o equilíbrio entre o educativo e o lúdico. Outro aspecto importante é o teste do jogo, por parte do professor, pois é de suma importância que o docente o experimente antes de levá-lo a sala de aula, ou seja, que ele vivencie a atividade de jogar (CUNHA, 2012). Com isso, o professor não é surpreendido por qualquer empecilho que surja ao longa da atividade com os alunos.

Segundo Cunha (2012), os jogos, quando levados à sala de aula, devem proporcionar ao estudante modos diferenciados para aprendizagem de conceitos. Um dos seus princípios deve ser a valorização das ações do sujeito que aprende, sendo esse mais importante que o conceito a ser aprendido.

Os aspectos lúdicos e cognitivos presentes no jogo podem ser importantes estratégias para o processo ensino-aprendizagem de conceitos abstratos e complexos, difíceis de serem absorvidos e compreendidos dentro das metodologias tradicionais (VASCONCELOS et al, 
2012). Uma atividade lúdica pode ser um instrumento de informação, observação e correlação dos conhecimentos adquiridos em sala de aula com o cotidiano do aluno, levando-o a perceber visualmente o que aprendeu na teoria (VASCONCELOS et al, 2012). Os recursos lúdicos podem conectar o aluno com a realidade, o que é fundamental para o aprendizado das ciências exatas, especialmente a Química (SANTOS, SILVA e MOLINA, 2013).

Além disso, os jogos didáticos podem ser instrumentos que motivam, atraem e estimulam o processo de construção do conhecimento (CUNHA, 2012). Esse tipo de jogo pode ser definido como uma ação divertida, seja qual for o contexto linguístico, desconsiderando o objeto envolto na ação (SOARES, 2004). Além disso, as aulas que estimulam, motivam e despertam o interesse dos alunos podem facilitar o processo de ensino-aprendizagem (LIBÂNEO, 1994). E nesse sentido, os jogos educacionais podem ser boas opções.

O jogo pode ter o objetivo de propiciar o meio para que o aluno induza o seu raciocínio, a reflexão e, consequentemente, a construção do seu conhecimento (LIMA et. al., 2011). Pode promover a construção do conhecimento cognitivo, físico, social e psicomotor, o que o leva a memorizar e/ou assimilar mais facilmente um assunto abordado (LIMA et. al., 2011).

Em continuidade, existem alguns critérios de validação para considerar um jogo como educacional. Os critérios e métodos de validação são importantes para a elaboração dos jogos didáticos, pois, por meio deles, será possível mensurar a efetividade do jogo para o processo ensino-aprendizagem. Os principais critérios descritos na literatura são: (1) interação ente os jogadores, (2) dimensão de aprendizagem, (3) jogabilidade, (4) aplicabilidade, (5) poder de desafio, (6) limitação de espaço e tempo e (7) criatividade (ALMEIDA et. al., 2017; ALVES et. al., 2016).

A interação entre os jogadores avaliará se jogo apresenta potencialidade de cooperação e/ou competição entre os participantes. A dimensão da aprendizagem avalia se o jogo visa a aprendizagem, se pode ser utilizado para testar conhecimentos construídos e se é direcionado para a memorização de dados ou fatos de maneira adequada. A jogabilidade mensura se a jogabilidade do jogo é simples e se propicia a imersão necessária. A aplicabilidade observa se o jogo permite variações na aplicação. O poder de desafio observa se o jogo desafia o jogador e se é apresentado como uma situação que busque o engajamento dos estudantes. O critério de limitação de espaço e tempo medirá se o jogo apresenta limitações de espaço adequadas para a sala de aula e se o jogo pode ser aplicado em tempo adequado para as aulas. Por fim, a criatividade avaliará se jogo considera situações em que a criatividade seja considerada (ALMEIDA et. al., 2017; ALVES et. al., 2016).

Nesse contexto, o objetivo deste trabalho é desenvolver um novo jogo didático para dispositivos móveis, abordando o conteúdo de funções orgânicas. O ensino de funções 
orgânicas para o Ensino Médio já foi investigado devido à dificuldade de aprendizagem dos alunos e também devido à complexidade do conteúdo (PAZINATO et. al., 2012; SILVA et. al., 2018). Além disso, almejou-se também o relato de aplicação e validação desse jogo com alunos do Ensino Médio e do Ensino Superior (futuros professores de Química).

\section{Metodologia}

A metodologia adotada neste trabalho foi a de pesquisa qualitativa, nos quais os dados coletados são predominantemente descritivos, a preocupação com o processo é maior do que com o produto e a análise dos dados tende a seguir um processo indutivo (LUDKE e ANDRÉ, 1986). Dentre as formas de pesquisa qualitativa, utilizou-se o estudo de caso, constituído de três fases principais no desenvolvimento: fase aberta ou exploratória, fase de coleta de dados e a fase de interpretação e análise dos dados (LUDKE e ANDRÉ, 1986). A coleta de dados foi realizada por observações e aplicação de questionários. O público envolvido na pesquisa foram alunos do Ensino Médio e Ensino Superior.

\subsection{ACESSO À INTERNET POR ALUNOS DO ENSINO MÉDIO}

Inicialmente, realizou-se uma investigação para observar se os alunos da rede estadual de ensino de Goiás tinham acesso à internet e qual o meio utilizado para realizar esse acesso. Com isso, aplicou-se um questionário para 76 alunos do primeiro ano do Ensino Médio de três escolas estaduais localizadas no município de Luziânia-GO. Todos os alunos participaram da atividade de forma voluntária no mesmo turno das aulas. O questionário foi composto por três perguntas, e pode ser visto no Quadro 1.

Quadro 1 - Questionário aplicado aos alunos de Ensino Médio, contendo informações sobre o acesso à internet

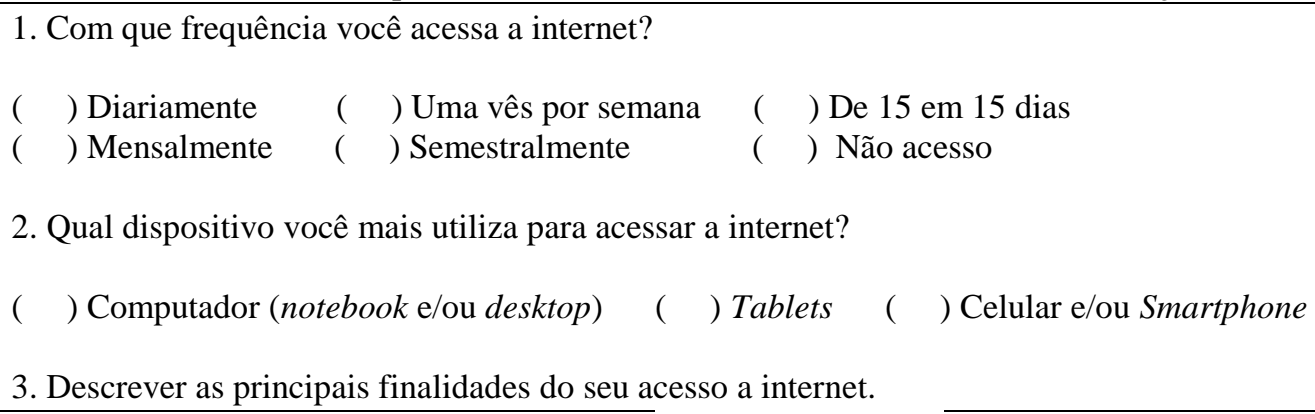

Fonte: próprio autor.

\subsection{DESENVOLVIMENTO DO JOGO}

Realizou-se o desenvolvimento de um jogo no formato de aplicativo para dispositivos móveis, abordando o conteúdo de funções orgânicas (alcano, aldeído, cetona, álcool e amina). O desenvolvimento foi fundamentado em um jogo conhecido e muito difundido entre os jovens, 
chamado de Candy Crush. Esse jogo apresenta mais de 500 milhões de downloads na Play Store (serviço de distribuição de aplicativos desenvolvido e operado pela Google).

O jogo recebeu o nome de Quimi Crush e foi criado utilizando o framework de desenvolvimento de jogos Unity3D e também o Adobe Illustrator (RODRIGUES e SILVA, 2010). O Unity3D utiliza a linguagem de programação C\# (RODRIGUES e SILVA, 2010). Utilizou-se alguns conceitos de ferramentas, como: linguagem de programação C\#, variáveis, declarações e vetores, implementação de efeitos sonoros, música de fundo e efeitos de partículas, assim como detectar colisões, receber entrada de usuários e criar movimento de jogadores. O Adobe Illustrator foi utilizado para o design e a criação de imagens vetoriais (RODRIGUES e SILVA, 2010) em 2D. O jogo e as regras estão detalhados nos resultados e discussão. Além disso, o Quimi Crush está disponível na Play Store de forma gratuita.

\subsection{APLICAÇÃO DO JOGO COM ALUNOS DO ENSINO MÉDIO}

Realizou-se a aplicação do jogo desenvolvido com 40 alunos de duas turmas de terceiro ano do Ensino Médio de uma escola federal de ensino, no município de Luziânia-GO. Primeiramente, fez-se uma breve apresentação do que era o jogo, o motivo pelo qual foi desenvolvido e seus objetivos. Em seguida, pediu-se aos alunos para baixarem o jogo em seus dispositivos móveis em uma plataforma digital (Play Store), e foi dado um tempo médio de 10 minutos para executarem a instalação do jogo. Em continuidade, leu-se as regras do jogo e realizou-se uma breve revisão das funções orgânicas presentes na atividade, etapa que teve 25 minutos de duração. Abriu-se espaço para os alunos esclarecerem eventuais dúvidas referente as regras e/ou as funções orgânicas revisadas. Logo após sanar todas as dúvidas, os alunos foram instruídos a iniciarem o jogo, com duração média de 15 minutos. Por fim, os alunos foram convidados a responderem um questionário avaliativo contendo dez questões, de forma voluntária (Quadro 2).

Quadro 2 - Questionário aplicado aos alunos do Ensino Médio referente a avaliação do jogo em sala de aula.

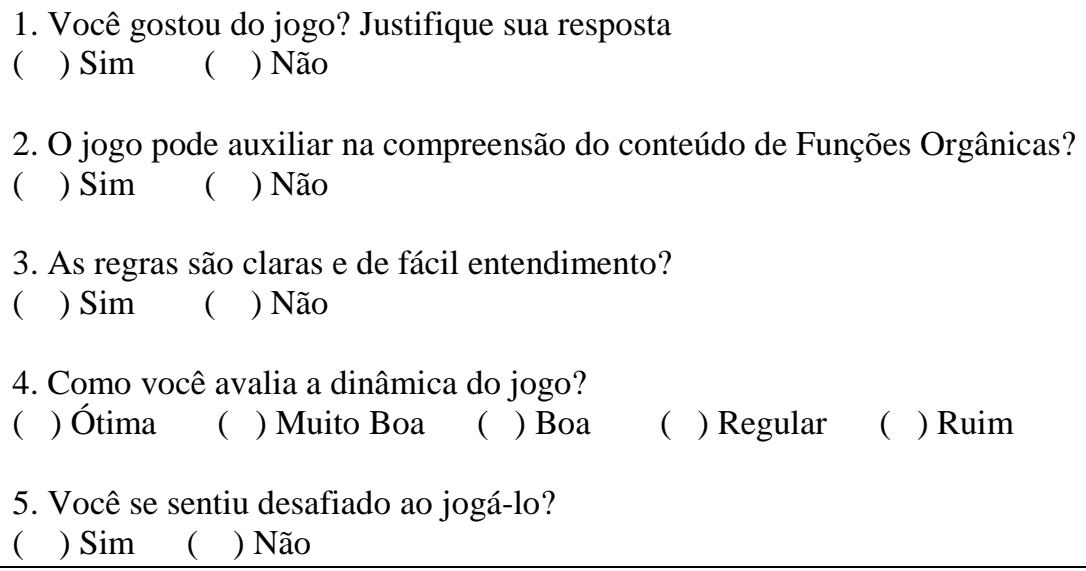


6. Como você avalia a qualidade do jogo?
( ) Ótima ( ) Muito Boa ( ) Boa
( ) Regular ( ) Ruim

7. Você acha o jogo adequado para a aplicação em ambiente escolar? Justifique sua resposta

( ) Sim ( ) Não

8. O que você acha que poderia ser melhorado no jogo?

9. Você pretende continuar usando esse jogo? Por quê?

10. Você já teve contato com jogos educacionais em outras disciplinas? Quais?

( ) $\operatorname{Sim}($ ) Não

Fonte: próprio autor.

\subsection{APLICAÇÃO DO JOGO COM ALUNOS DO ENSINO SUPERIOR}

Realizou-se a aplicação do jogo desenvolvido com 10 alunos do quinto e sexto semestre do curso de Licenciatura em Química de uma instituição federal de ensino, no município de Luziânia-GO. Primeiramente, fez-se uma breve apresentação do que era o jogo, o motivo pelo qual foi desenvolvido e seus objetivos. Em seguida, pediu-se aos futuros professores para baixarem o jogo em seus dispositivos móveis em uma plataforma digital (Play Store), e foi dado um tempo médio de 10 minutos para executarem a instalação do jogo. Em continuidade, leu-se as regras do jogo e realizou-se uma breve revisão das funções orgânicas presentes na atividade, etapa que teve 20 minutos de duração. Abriu-se espaço para os alunos esclarecerem eventuais dúvidas referente as regras e/ou as funções orgânicas revisadas. Logo após sanar todas as dúvidas, os alunos foram instruídos a iniciarem o jogo, com duração média de 15 minutos.

Por fim, os futuros professores foram convidados a responderem um questionário avaliativo contendo dez questões, de forma voluntária (Quadro 3).

Quadro 3 - Questionário aplicado aos alunos do Ensino Superior referente a avaliação do jogo em sala de aula
1. Você gostou do jogo? Justifique sua resposta
( ) Sim ( ) Não
2. O jogo pode auxiliar na mediação do conteúdo de Funções Orgânicas?
( ) $\operatorname{Sim}($ ) Não
3. As regras são claras e de fácil entendimento?
( ) Sim ( ) Não
4. Como você avalia a dinâmica do jogo?
( ) Ótima ( ) Muito Boa ( ) Boa ( ) Regular ( ) Ruim
5. Você se sentiu desafiado ao jogá-lo?
( ) $\operatorname{Sim}($ ) Não
6. Como você avalia a qualidade do jogo?
( ) Ótima ( ) Muito Boa ( ) Boa ( ) Regular ( ) Ruim
7. Você acha o jogo adequado para a aplicação em ambiente escolar? Justifique sua resposta 


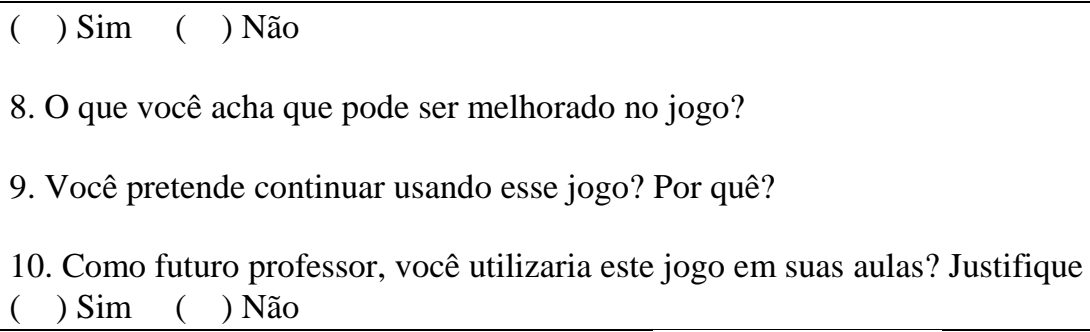

Fonte: próprio autor.

\section{Resultados}

\subsection{ACESSO À INTERNET POR ALUNOS DO ENSINO MÉDIO}

Dos 76 alunos que responderam ao questionário, 72 alunos $(94,8 \%)$ afirmaram acessar a internet diariamente. Outros 2 alunos (2,6\%) afirmaram que acessam semanalmente e 2 alunos $(2,6 \%)$ que afirmaram acessar mensalmente. Nenhum aluno relatou acessar a internet de quinze em quinze dia, semestralmente ou não acessar a internet. Além disso, 63 alunos $(79,4 \%)$ declararam acessar a internet em celulares e/ou smartphones e 13 alunos (20,6\%) acessam via computador. Nenhum aluno afirmou acessar via tablets. Nota-se que a grande maioria dos alunos acessam a internet diariamente, frequência extremamente alta. Além disso, telefones celulares e smartphones são os principais meios de acesso para a internet. Assim, é possível utilizar esse grande contato dos jovens com as novas tecnologias, como internet e smartphones, em benefícios da educação (REIS, SILVA e LEÃO, 2017).

Os jogos didáticos para dispositivos móveis podem ser uma boa alternativa para o ensino de qualquer disciplina. Constantemente note-se o desconforto de alguns professores com o uso de celulares pelos alunos, em sala, para fins não educacionais. Entretanto, o celular é um instrumento presente na vida dos alunos, e coibir seu uso em sala de aula pode ir contra ao rápido avanço das tecnologias que estão presentes na vida dos jovens. Com isso, pode-se usar este fato a favor da educação, incentivando seu uso para fins didáticos.

Quando se questionou as principais finalidades do acesso à internet, os alunos poderiam descrever mais de uma resposta. As principais respostas foram: para estudar (59 respostas $77,6 \%$ ), acessar redes sociais (52 respostas - 68,4\%) e jogos e vídeos (40 respostas $-52,6 \%$ ). Nota-se um grande interesse dos alunos em utilizar a internet para estudar e para jogar. Assim, é importante notar o potencial didático existente na união dessas duas atividades em benefício do Ensino. Essa união, pode tornar o ato de aprender mais prazeroso e divertido, e nesse sentido, as atividades lúdicas educacionais, aliadas as novas tecnologias, podem ser uma ferramenta de grande importância para a educação (SOARES, 2004; CUNHA, 2012). 


\subsection{DESENVOLVIMENTO DO JOGO}

Realizou-se o desenvolvimento de um aplicativo, denominado Quimi Crush. Esse jogo aborda o conteúdo de funções orgânicas, geralmente abordado no terceiro ano do ensino médio. A tela inicial do jogo Quimi Crush apresenta as opções de iniciar o jogo ("Jogar”) e visualizar as regras ("Regras") (Figura 1). O jogo consiste em selecionar duas estruturas Químicas adjacentes para trocá-las de posição (Figura 2). Para jogar, deve-se juntar três ou mais estruturas com funções orgânicas iguais e elas desaparecerão, seja em uma combinação vertical ou horizontal. Ao combinar quatro ou mais estruturas iguais, forma-se uma peça especial com o nome da função orgânica (Figura 2). Com ela, é possível combinar o nome da função orgânica com a estrutura e eliminar toda uma linha vertical ou horizontal. Quanto mais as estruturas são eliminadas, maior será a pontuação acumulada. O jogo acaba quando 300 mil pontos são acumulados.

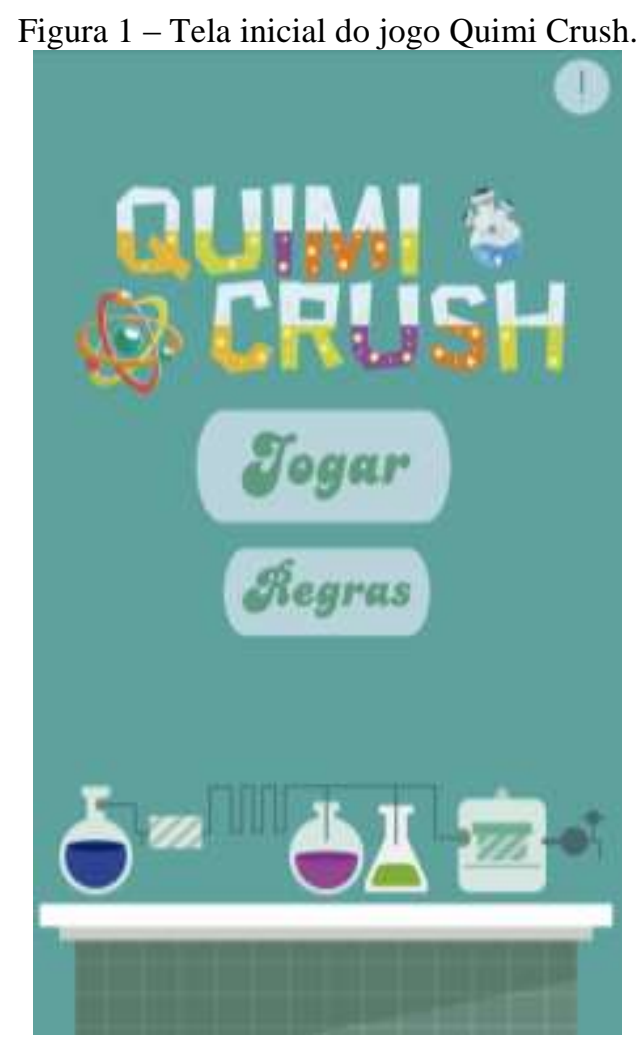

Fonte: próprio autor.

Grupos funcionais iguais devem ser agrupadas para desaparecerem. Para isso, é necessário realizar trocas de posição, podendo ocorrer na vertical ou horizontal. Nota-se também (Figura 2 a direta) as peças especiais (com o nome da função orgânica) que surgem ao combinar 4 ou mais estruturas iguais. Quando as peças especiais (nome da função orgânica) são combinadas com as respectivas fórmulas estruturais, toda uma linha horizontal ou vertical é 
eliminada. Quanto mais peças são eliminadas, maior será a pontuação. A pontuação pode ser vista no canto inferior direito.

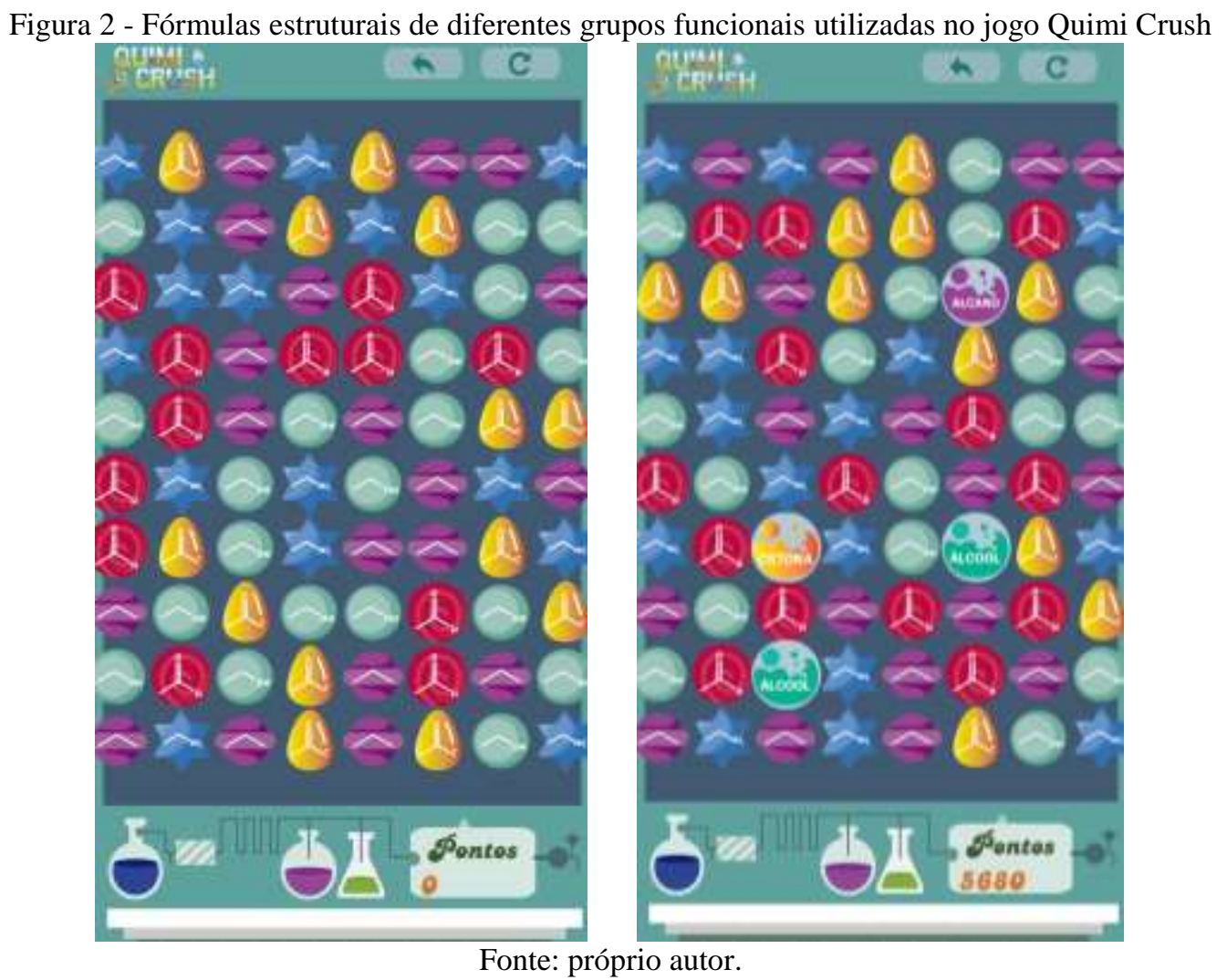

Devido a algumas dificuldades encontradas, os conteúdos de funções orgânicas, para o Ensino Médio, foram motivos de inúmeras investigações para tentar melhorar o processo de ensino-aprendizagem desse assunto. Com isso, algumas estratégias didáticas foram propostas para tentar alcançar tais objetivos (PAZINATO et. al., 2012; SILVA et. al., 2018; DINIZ JR e SILVA, 2016). Dessa forma, o jogo Quimi Crush pode ser uma alternativa interessante para melhorar e dinamizar o processo de ensino e aprendizagem de funções orgânicas, tentando unir jogo, educação e novas tecnologias, assuntos de grande interesse entre os jovens.

Além disso, escolheu-se desenvolver este jogo fundamentando no Candy Crush com o objetivo de proporcionar maior familiaridade dos alunos com o jogo e com as regras, o que pode facilitar o ato de jogar (jogabilidade) (CUNHA, 2012).

\subsection{APLICAÇÃO DO JOGO COM ALUNOS DO ENSINO MÉDIO}

Ao longo da atividade, notou-se grande entusiasmo e interesse dos alunos pelo Quimi Crush. Foi nítido um aumento no interesse pela atividade, além de maior concentração nas falas do professor, havendo pouca conversa paralela e distrações. Durante o jogo, observou-se ainda uma interação aluno-aluno, em que um estudante comparava sua pontuação com outros 
estudantes, além de interação aluno-professor, em que os estudantes apresentavam suas dúvidas para o professor. Notou-se que a relação impessoal entre professor e aluno foi deixada de lado durante a atividade.

Analisando a primeira pergunta do questionário aplicado aos alunos do Ensino Médio, 97,5\% responderam ter gostado do jogo, e 2,5\% afirmaram não terem gostado. Nota-se que o jogo desenvolvido agradou a maioria dos alunos, e tal fato pode ser comprovado por algumas justificativas apresentadas pelos alunos: "é uma maneira legal de se aprender função orgânica, e como é um conteúdo que estou aprendendo agora, vai ser muito útill" (aluno 1), "achei muito dinâmico e de fácil entendimento, principalmente para iniciantes da matéria” (aluno 2) e “interessante a mistura do lúdico com a parte educacional" (aluno 3). O aluno que declarou não gostar o jogo não apresentou a justificativa. Segundo Alcará e Guimarães (2007), o sucesso para uma atividade educacional realizada em sala de aula pode estar relacionado com a motivação dos alunos. Assim, o que agrada os alunos pode ser o primeiro passo para despertar o interesse e motivar para a atividade de aprendizado.

Referente a segunda pergunta do questionário, 95\% acreditam que o jogo pode auxiliar na compreensão do conteúdo em questão, e 5\% afirmaram que não. Segundo Zub (2012), os jogos didáticos podem melhorar o interesse dos alunos pelas aulas, podendo auxiliar na compreensão de conteúdos abstratos. E nesse sentido, os alunos reconhecem que o Quimi Crush pode ser uma ferramenta para melhorar a compreensão do conteúdo, o que torna esse jogo uma alternativa para ensinar ou revisar este tipo de conteúdo na sala de aula.

Observando a terceira pergunta do questionário, 100\% dos alunos afirmaram que as regras do jogo são claras e de fácil entendimento. Segundo Cunha (2012), a falta de clareza e o não entendimento da regra pode prejudicar o andamento da atividade, fazendo com que o objetivo traçado pelo professor não seja alcançado. Não é possível jogar se as regras não forem compreendidas pelos jogadores. O Quimi Crush, de acordo com os alunos, conseguiu apresentar regras claras e de fácil entendimento, o que pode facilitar a jogabilidade.

Para a quarta pergunta do questionário, $10 \%$ dos alunos avaliaram a dinâmica do jogo como ótima, $50 \%$ como muito boa, $37,5 \%$ como boa, $2,5 \%$ como regular e nenhuma avaliação como ruim. Com regras claras e uma boa dinâmica, notou-se que a atividade apresentou boa “jogabilidade" e fluidez, o que pode permitir que o conteúdo de funções orgânicas fosse apresentado de forma mais dinâmica.

Analisando a quinta pergunta do questionário, 65\% dos alunos afirmaram que se sentirem desafiados com o jogo, e 35\% disseram que não se sentiram desafiados. Segundo Almeida (2017) e Alves (2016), o poder de desafio e o estímulo a criatividade são critérios para 
validar um jogo como educacional. O Quimi Crush, na visão dos alunos, conseguiu estimular o desafio e a criatividade.

Referente a sexta pergunta do questionário, $20 \%$ dos alunos avaliaram a qualidade do jogo como ótima, 37,5\% como muito boa, $27,5 \%$ como boa, 2,5\% como regular e nenhuma avaliação como ruim. A qualidade do jogo agradou a maioria dos alunos, sendo essa característica um ponto chave para despertar o interesse dos alunos pela atividade. Um jogo com má qualidade pode contribuir para o desinteresse da situação, fazendo o jogo perder o sentido de ser utilizado.

Observando a sétima pergunta do formulário, 90\% dos alunos acreditam que o jogo é adequado para a utilização em ambiente escolar, e 10\% acreditam que não. Um dos principais objetivos de um jogo didático é que o ele seja adequado para ser trabalho em sala de aula. $\mathrm{O}$ Quimi Crush recebeu uma boa avaliação dos alunos. As principais justificativas dos alunos para as repostas foram: "é uma forma Lúdica de aprender" (aluno 13), "é dinâmico e bem funcional" (alunos 27) e "o jogo pode ao mesmo tempo divertir e ensinar, mostrando um lado divertido da Química" (aluno 29). Nota-se que os alunos correlacionaram o lúdico com a parte educacional, mostrando que uma atividade lúdica educacional deve ter um equilíbrio entre o divertimento e o prazer com a dimensão de aprendizagem (CUNHA, 2012).

Para a oitava questão, 75\% dos alunos não apresentaram nenhuma sugestão para melhorar o jogo, e 25\% apresentaram sugestões de melhoras. Nota-se que o jogo agradou a maioria dos alunos, em que estes não apresentaram nenhuma sugestão de melhoria. Dentre os alunos que apresentaram sugestões para melhorar, todas as repostas foram baseadas em aumentar o número de "fases" e apresentar diferentes níveis de dificuldades para o jogo, como pode ser observado nas falas: "ter níveis de dificuldade e uma pontuação maior" (alunos 9), "ser criado um sistema de fases" (aluno 27) e "colocar mais níveis e aumentar a dificuldade" (aluno 29). Tais sugestões foram avaliadas de forma positiva, e uma atualização do jogo, com diferentes fases, deve ser lançada no futuro.

Analisando a nona questão do formulário, $72,5 \%$ dos alunos afirmaram que pretendem continuar usando o jogo e 27,5\% afirmaram que não jogarão novamente. As principais justificativas para os alunos que continuarão jogando foram: "achei um jogo bastante divertido" (aluno 4), "por ser divertido, com ótima interação com o usuário e para o aprendizado" (aluno 6) e, "pois, me auxiliou no conteúdo" (aluno 34). Observa-se que a maioria dos alunos demostrou grande interesse pelo jogo, tanto que pretendem continuar usando o jogo. Segundo Libâneo (1994), o ensino deve ser dinâmico para motivar o aluno, e nesse sentido, o Quimi Crush pode ser uma ferramenta util. As principais justificativas para não continuarem a usar o 
jogo foram: "pois já atingi o objetivo do jogo" (aluno 19) e "pois não tem mais níveis" (aluno 20). Tais justificativas foram as mesmas observadas como sugestão de melhoria para o jogo, e espera-se superar este obstáculo com uma nova versão atualizada do jogo, contendo mais fases e diferentes níveis de dificuldade.

Referente a última pergunta do questionário, 50\% dos alunos afirmaram que haviam tido contato com jogos educacionais em outras disciplinas, e 50\% afirmaram que não. Apenas três disciplinas foram citadas com a presença de jogos em sala de aula (Português, Matemática e Inglês), e apenas dois jogos foram citados ("Kahoot" e "Duolingo"). Apesar da grande importância que os jogos educacionais pode trazer para o ensino (CUNHA, 2012), nota-se que esses são recursos pouco utilizados em sala de aula. Além disso, nenhum aluno teve contato com as atividades lúdicas nas aulas de Química. Nessa perspectiva, o Quimi Crush pode ser uma boa alternativa para dinamizar e melhorar o interesse dos alunos pelas aulas de Química.

Além disso, segundo Almeida (2017) e Alves (2016), existem alguns critérios para validar um jogo como educacional, que são: (1) interação entre jogares; (2) dimensão de aprendizagem; (3) jogabilidade; (4) aplicabilidade; (5) poder de desafio; (6) limitação de espaço e tempo e (7) criatividade. Nessa perspectiva, o Quimica Crush consegue atender a maioria dos critérios de validação, podendo ser utilizado como um jogo didático para auxiliar as aulas de Química.

O único critério que o jogo não conseguiu atender foi o de interação entre jogadores (critério 1), visto que o jogo foi planejado para ser joga individualmente. Entretanto, isso não impede que o Quimi Crush seja inserido em alguma atividade em grupo para melhorar a interação entre os alunos. Observando o critério 2, o Quimi Crush visa a aprendizagem, podendo ser utilizado para testar conhecimentos construídos sobre funções orgânicas. Analisando a jogabilidade, o jogo é simples, com regras claras e propicia a imersão necessária para a atividade. Além disso, as regras e a dinâmica do jogo foram bem avaliadas pelos alunos, atestando uma boa jogabilidade.

Referente ao critério 4, o jogo permite variações em sua aplicação, o que pode apresentar uma boa aplicabilidade. Analisando o poder de desafio, a maioria dos alunos responderam que se sentiram desafiados com o jogo, mostrando que os estudantes podem demostrar maior engajamento pela atividade. Observando o critério 6, o jogo não apresenta problemas de limitação de espaço ou tempo e pode ser jogado na própria sala de aula ou qualquer outro ambiente. Além disso, o Quimi Crush pode ser utilizado tranquilamente em aulas de 40 ou 50 minutos de duração, não necessitando de muito tempo para que os alunos comecem a jogar. Por 
fim, pode-se considerar que o jogo busca despertar a criatividade nos alunos. Nessa visão, o Quimi Crush consegue ser validado como um jogo didático.

\subsection{AplicaÇão do Jogo Com Alunos do EnSINo SuPERIOR}

Notou-se um grande interesse dos alunos pela atividade. Entretanto, os alunos do curso superior não apresentaram tanto entusiasmo como os alunos do Ensino Médio. Além disso, notou-se grande curiosidade dos alunos acerca do desenvolvimento do jogo, em que eles apresentaram várias perguntas sobre a o modo de realizar o desenvolvimento de um aplicativo para a Química.

Referente a primeira pergunta do questionário aplicado aos futuros professores de Química, 90\% responderam ter gostado do jogo, e 10\% responderam que não gostaram. Notase que a maioria dos licenciados se interessou pelo jogo, como pode ser observada em na resposta: "um jogo muito interessante e um grande auxílio no processo de ensinoaprendizagem, pois o aluno aprende jogando" (licenciando 1). O aluno que não gostou do jogo não apresentou uma justificativa. Segundo Gomes e Merquior (2017), uma atividade lúdica educacional pode ser caracterizada por apresentar os conteúdos de uma forma mais atrativa. Nessa perspectiva, os futuros docentes podem usar o Quimi Crush para tentar instigar o interesse dos alunos pelas aulas. Um ponto de partida para um professor levar um jogo para a sala de aula é quando o docente gosta do jogo. Caso o jogo não agrade o professor, é difícil esse jogo ser utilizado como ferramenta didática. Nessa perspectiva, o Quimi Crush apresentou uma boa receptividade por parte dos futuros professores.

Observando a segunda pergunta do questionário, 100\% dos licenciados afirmaram que o jogo pode auxiliar na mediação do conteúdo. Garcez (2014) afirma que, o professor deve utilizar diferentes estratégias de ensino, podendo, com isso, conquistar o interesse dos alunos pela aula. Nesse sentido, o Quimi Crush pode ser uma boa opção para o professor diferenciar a metodologia adotada para a aula e para auxiliar na mediação de funções orgânicas.

Em relação a terceira pergunta do formulário, $100 \%$ dos futuros professores afirmaram que o jogo apresenta regras claras e de fácil entendimento. Assim como na avaliação dos alunos de ensino médio, os alunos do superior avaliaram as regras como claras e de fácil entendimento. Como afirma Cunha (2012), a falta de clareza nas regras pode levar a atividade ao fracasso, pois quem não entende a regra, apresenta dificuldade em jogar, o que pode gerar o insucesso para o planejamento do professor.

Referente a quarta pergunta do questionário, 30\% dos licenciandos avaliaram a dinâmica do jogo como ótima, $50 \%$ como muito boa, $10 \%$ como boa, $10 \%$ como regular e 
ninguém avaliou a dinâmica como ruim. Assim como avaliado pelos alunos do Ensino Médio, os futuros docentes analisaram de forma positiva a dinâmica do jogo, o que pode tornar o Quimi Crush uma boa alternativa para dinamizar as aulas de Química, tornando-as mais prazerosas e divertidas.

Observando a quinta pergunta do formulário, $90 \%$ dos futuros professores afirmaram que se sentiram desafiados com o jogo, enquanto que $10 \%$ afirmaram que não se sentiram desafiados. Assim como a maioria dos alunos do Ensino Médio, a maioria dos graduandos se sentiram desafiados, sendo este um critério para validar um jogo como educacional (ALMEIDA et. al., 2017; ALVES et. al., 2016), e nessa perceptiva, o jogo atendeu a esse critério.

Em relação a sexta pergunta do questionário, $20 \%$ dos licenciados avaliaram a qualidade do jogo como ótima, $60 \%$ como muito boa, $10 \%$ como boa, $10 \%$ como regular e ninguém avaliou como ruim. Novamente a qualidade do jogo foi bem avaliada, o que pode contribuir para um maior interesse dos alunos pelo jogo, e por consequência, tentar melhorar o interesse pelas funções orgânicas. Um jogo que apresenta a qualidade ruim pode não despertar o interesse dos estudantes.

Analisando a sétima pergunta do formulário, $90 \%$ dos futuros professores acreditam ser adequada a aplicação do jogo em ambiente escolar, enquanto que $10 \%$ afirmaram que não acham adequada essa aplicação. As principais justificativas para as respostas foram: "é um jogo que ajuda bastante no conteúdo de Funções Orgânicas, e ao mesmo tempo é divertido" (licenciando 3) e "ajuda e reconhecer as funções orgânica" (licenciando 4). Nota-se que os graduandos correlacionaram a parte lúdica com a parte de conhecimento científico, sendo de extrema importância que um jogo educacional tenha um equilíbrio entre essas partes (CUNHA, 2012). Além disso, os graduandos alegam que o jogo pode ser adequado para o ambiente escolar por acreditaram que o jogo pode auxiliar na mediação de funções orgânicas, sendo este um dos objetivos do jogo.

Referente a oitava pergunta do questionário, $80 \%$ dos licenciandos não apresentaram sugestão de melhora para o jogo, e $20 \%$ apresentaram sugestões. Novamente notou-se que o jogo agradou a maioria dos futuros professores. Dentre os graduandos que apresentaram sugestões de melhora, novamente todos as repostas foram baseadas em aumentar o número de "fases" para o jogo, como pode ser visto em algumas falas: "novos objetivos e desafios maiores" (licenciando 1) e "a adição de novos níveis" (licenciando 5). Está prevista uma atualização para o jogo no futuro, em que novas fases serão desenvolvidas.

Observando a nona pergunta do questionário, $90 \%$ dos futuros docentes afirmaram que pretendem continuar usando o jogo, e 10\% afirmaram que não pretendem. As principais 
justificativas para os discentes que afirmaram que pretendem continuar usando o jogo foram: "vai me auxiliar muito para o estudo de química orgânica, e eu, como futuro professor, poderia utilizá-lo como um auxílio na sala de aula" (licenciando 2) e "poderá auxiliar no aprendizado dos meus alunos" (licenciando 8). Os graduandos que não pretendem mais utilizar o jogo não justificaram suas respostas. Analisando a décima pergunta do formulário, $100 \%$ dos licenciados afirmaram que, como futuros professores, utilizariam esse jogo em suas aulas. As principais justificativas apresentadas foram: "ajudaria a reconhecer as funções" (licenciando 4) e "irá auxiliar os alunos no estudo de química orgânica" (licenciando 1).

Nota-se que os futuros professores reconhecem que o Quimi Crush pode ser uma ferramenta de grande ajuda para ser utilizado em sala de aula, tanto que todos afirmam que utilizariam o jogo em suas aulas, podendo esse auxiliar na mediação do conteúdo de funções orgânicas. O jogo desenvolvido apresenta características que podem torná-lo uma ferramenta didática bastante útil para as aulas de Química no Ensino Médio.

Além disso, segundo a teoria de aprendizagem tangencial, esta ocorre quando o estudante apresenta contato com o conhecimento, sem notar a intenção de ensiná-lo (LEITE, 2015). Nesse caso, os jogos em dispositivos móveis, como o Quimi Crush, podem proporcionar tal ambiente para um aprendizado tangencial, podendo promover um processo agradável e eficiente de aprendizado. Mesmo que a aprendizagem não ocorra dentro do próprio jogo, consegue-se despertar um maior interesse voluntário sobre o assunto, se tornando importante para o ensino (LEITE, 2015).

Ainda nessa perspectiva, a teoria da aprendizagem conectada aborda a importância da utilização de meios digitais para ampliar o acesso a novas oportunidades e experiências de aprendizagem significativa (LEITE, 2015). Nesse sentido, tal teoria destaca que os alunos podem aprender melhor quando estão mais interessados pelo o que estão aprendendo, o que pode ser auxiliados por novas tecnologias, como o Quimi Crush, para dispositivos móveis (LEITE, 2015). Com isso, o aluno consegue conectar seus interesses (dispositivos móveis, tecnologias e diversão) com o estudo acadêmico, o que pode ser um grande aliado para o ensino.

\section{CONSIDERaÇões FinaIS}

Foi possível realizar o desenvolvimento de um jogo, chamado de Quimi Crush, que aborda os conteúdos de funções orgânicas. O jogo foi planejado para ser utilizado em aulas de Química Orgânica do Ensino Médio. Além disso, o Quimi Crush foi idealizado para ser jogado pelo celular, aproveitando o grande contato e interesse dos alunos pelos smartphones, tentando correlacionar as notas tecnologias com assuntos educacionais. 
O jogo foi testado e aplicado com alunos do Ensino Médio e do Ensino Superior, agradando ambos os grupos, podendo ser uma boa alternativa para dinamizar as aulas de Química e auxiliar na mediação do conteúdo de funções orgânicas. Além disso, o Quimi Crush foi validado para uma atividade lúdica didática, podendo ser uma alternativa para novas metodologias em sala de aula.

\section{REFERÊNCIAS}

ALCARÁ, A. R.; GUIMARÃES, S. E. R. A Instrumentalidade como uma estratégia motivacional. Psicologia Escolar Educacional, v. 11, n.1, p. 177-178, 2007.

ALMEIDA, H. C. R.; SILVA, C. M. J.; SILVA, J. C. S.; SIMÕES NETO, J. E. Percepção Dos Licenciados em Química Sobre a aplicação de Jogos da Química II. Revista Eletrônica Ludus Scientiea, v.1, n. 01, p. 126-141, jan/jul, 2017.

ALVES, C. T.; SILVA, J. C. S.; SILVA, R. B.; SIMÕES NETO, J. E. Elaboração e Validação de Jogos Didáticos Propostos por Estudante do Ensino Médio. Revista Eletrônica Debate Em Ensino de Química. v. 2, n. 2, p. 47-54, 2016.

CAVALCANTI, E. L. D.; SOARES, M. H. F. B. O uso de jogos de roles (roleplaynig game) como estratégia de discussão e avaliação do conhecimento químico. Revista Eletrônica de Ensenânza de Las Ciencias. v. 8, p-255-282, 2009

CUNHA, M. B. Jogos no Ensino de Química: Considerações teóricas para sua utilização em sala de aula. Revista Química Nova na Escola. v. 34, p. 92-98. 2012.

DIAS, M. C. M. Metáfora e Pensamento: considerações sobre a importância do jogo na aquisição do conhecimento e implicações para a educação. In: Jogo, Brinquedo, Brincadeira e Educação. KISHIMOTO, T. M. (org):. São Paulo, Editora Cortez, e. 4º, 1996

DINIZ Jr, A. I.; SILVA, J. R. R. T. Isômeros, Funções Orgânicas e Radicais Livres: Análise da Aprendizagem de Alunos do Ensino Médio Segundo a Abordagem CTS. Química Nova na Escola, v, 38, n. 1, p. 60-69, 2016.

GARCEZ, E.S.C. Jogos e atividades lúdicas em ensino de Química: um estudo do estado da arte. Goiânia, 2014. 149 p. Dissertação (Mestrado em Educação em Ciências e Matemática) - Pró-Reitora de Pesquisa e Pós-Graduação, Universidade Federal de Goiás, 2014.

GOMES, L. O.; MERQUIOR, D. M. O uso dos jogos e atividades lúdicas no Ensino Médio em Química. Revista UNIABEU, V.10, Número 24, janeiro-abril de 2017.

LEITE, B. S. Tecnologias no Ensino de Química. 1. ed. Curitiba: Appris, 2015.

LIBÂNEO, J. C. Didática. 2. ed. São Paulo: Cortez. 1994.

LIMA, E. C.; MARIANO, D. G.; PAVAN, F. M.; LIMA, A. A.; ARÇARI, D. P. Uso de Jogos Lúdicos Como Auxilio Para o Ensino de Química. Centro Universitário Amparaense, 2011. 
KISHIMOTO, T. M. O jogo e a educação infantil. In: (org). Jogo, Brinquedo,

Brincadeira e Educação. Editora Cortez, 1996.

SANTOS, C. F.; SILVA, F. J.; MOLINA, A. Os recursos lúdicos para o despertar para o aprendizado em ciências em escolas públicas. Projeto PIBID, Universidade Estadual de Mato Grosso do Sul, 2013.

SILVA, B.; CORDEIRO, M. R.; KIILL, K. B. Jogo Didático Investigativo: uma ferramenta para o ensino de química inorgânica. Revista Química Nova na Escola, v. 37, n. 1, p. 27-34, 2015.

SILVA, J. E.; SILVA Jr, C. N.; OLIVEIRA, O. A.; CORDEIRO, D. O. Pistas Orgânicas: um jogo para o processo de ensino e aprendizagem da química. Química Nova na Escola, v. 40, n. 1, p. 25-32, 2018.

SOARES, M. H. F. B. O Lúdico em Química: Jogo e atividades aplicados ou ensino de química, Universidades Federal de São Carlos, Tese de Doutorado, 2004.

PAZINATO, M. S.; BRAIBANTE, H. T. S.; BRAIBANTE, M. E. F.; TREVISAN, M. C.; e SILVA, G. S. Uma Abordagem Diferenciada para o Ensino de Funções Orgânicas através da Temática Medicamentos. Química Nova na Escola, v. 34, n. 1, p. 21-25, 2012.

PIAGET, J. A. A. Formação do Símbolo na Criança, Rio de Janeiro: Zahar, 1975

REIS, R. S.; SILVA, I. M.; LEÃO, M. B. C. Divulgação de Materiais Educacionais Suportados Pelas TIC para o Ensino de Química. Revista Tecnologias na Educação, n. 9, v. 23, p. 1-13, 2017.

RODRIGUES, L. B.; SILVA, J. C. Framework para Desenvolvimento de Jogos 3D Baseado na API O3D. Revista Eletrônica TECCEN, v. 3, n. 2, p. 97-110, 2010.

VASCONCELOS, E. S.; ROCHA, I. F.; SILVA, J. P.; CEZAR, K. L.; SOARES, P. S.; MOREIRA, T. S.; LORENZO, J. G. F.; SANTOS M. L. B. Jogos uma forma lúdica de ensinar, Congresso Norte Nordeste de Pesquisa e Inovação, ed 7², Palmas, 2012.

ZUB, L. O lúdico como motivador da aprendizagem em química para alunos da $1^{\circ}$ série do ensino médio do Colégio Estadual João XXIII em Irati - Paraná. 2012.127f.

Dissertação (Mestrado Profissional em Ensino de Ciência e Tecnologia) - Universidade Tecnológica Federal do Paraná, Ponta Grossa, 2012.

Recebido em: 27 de setembro de 2018.

Aprovado em: 4 de dezembro de 2018. 